\title{
Discursos Sobre Crime e Punição na Produção de Alternativas à Prisão no Brasil
}

Discourses on Crime and Punishment in the Production Of Alternatives to Imprisonment in Brazil

Discursos Sobre Crimen y Castigo en la Producción De Alternativas a La Prisión en Brasil

\section{Guilherme Augusto Dornelles de Souza}

Pontifícia Universidade Católica do Rio Grande do Sul, Bolsista CAPES (PROSUP II), Mestrando no Programa de Pós-Graduação em Ciências Criminais da PUCRS, especialista em Ciências Penais pela PUCRS e bacharel em Ciências Jurídicas e Sociais pela UFRGS. É pesquisador integrante do Grupo de Pesquisa em Políticas Públicas de Segurança e Administração da Justiça Penal (GPESC) e do Instituto de Estudos Comparados em Administração Institucional de Conflitos (INCT-InEAC). Atua também como analista no Ministério Público Federal.

E-mail: guilherme.augustus@gmail.com

\section{Resumo}

Este artigo apresenta uma análise dos discursos sobre crime e punição presentes no processo de proposição, discussão, aprovação e sanção da leis 7.209/84, 9.605/98, 9.714/98 e 11.343/2006, que instituíram alternativas penais à pena privativa de liberdade. Propõe-se uma análise tática das alternativas penais, tomando os discursos implicados na sua construção como inseridos em um jogo estratégico. Evidencia-se as concepções sobre crime, sobre a punição e sobre os sujeitos criminalizados existentes nesses documentos e os modos como tais concepções foram mobilizadas em diferentes momentos para a produção de alternativas à prisão no Brasil. A análise mostra que a instituição de penas diversas da prisão esteve marcada por discursos centrados na identificação e diferenciação de sujeitos a quem devem ser destinadas diferentes respostas estatais, afirmando a necessidade de manutenção da prisão como pena, e por um modo gerencial e atuarial de pensar as práticas punitivas estatais oficiais.

Palavras-chave: Alternativas penais; Penas alternativas; Discursos; Crime; Punição

\begin{abstract}
This paper presents an analysis of the discourses on crime and punishment present in the law-making process of statutes n. 7.209/84, 9.605/98, 9.714/98 and 11.343/2006, which instituted alternatives to imprisonment in Brazil. It is proposed a tactical analysis of these sentencing
\end{abstract}


alternatives, taking the discourses involved in its construction as involved in a strategic game. Conceptions about crime, punishment and about the individual criminalized in these documents are made evident, as well as the ways these ideas were mobilized at different times for the production of alternatives to prison in Brazil. The analysis shows that the production of alternative punishments for crimes was marked by discourses focused on the identification and differentiation of individuals who should be targeted different state responses, affirming the need for continuation of imprisonment as a punishment, and an actuarial-managerial way of thinking the Criminal Justice's punitive practices.

Keywords: Alternatives to imprisonment; Community penalties; Discourses; Crime; Punishment

\section{Resumen}

Este trabajo presenta un análisis de los discursos sobre el crimen y el castigo presentes en el proceso legislativo de las leyes 7.209/84, 9.605/98, 9.714/98 y 11.343/2006, que instituyeron alternativas a la prisión en Brasil. Proponemos un análisis táctico de las penas alternativas, tomando los discursos que intervienen en su construcción como insertados en un juego estratégico. Se evidencia las concepciones sobre el crimen, el castigo y las personas incriminadas existentes en estos documentos, así como las formas en que estos conceptos fueron movilizados en diferentes momentos de la producción de alternativas a la cárcel en Brasil. El análisis muestra que la construcción de las penas alternativas fue marcada por discursos que se centraron en la identificación y diferenciación de las personas a que deben ser dirigidas las diferentes respuestas del Estado, necesitando mantener la prisión como pena, así como una manera actuarial y gerencial de pensar las prácticas punitivas estatales.

Palabras-clave: Alternativas penales; Penas alternativas; Discursos; Crimen; Castigo

\section{Introdução}

Este artigo apresenta discussões preliminares de uma pesquisa em andamento que tem por objetivo analisar os discursos implicados na construção de alternativas à prisão no Brasil a partir da reforma da parte geral do Código Penal em
1984 até a instituição da Estratégia Nacional de Alternativas Penais, pelo Ministério da Justiça, em 2011. Para a discussão proposta nesse artigo, fez-se um recorte para abordar os discursos sobre crime e punição presentes no processo de proposição, discussão, aprovação e sanção de algumas leis que instituíram alternativas à pena 
privativa de liberdade. Trata-se da Lei 7.209, de 1984, que reformou a parte geral do Código Penal, da Lei 9.605, de 1998, que tratou dos crimes ambientais, da Lei 9.714, de 1998, que ampliou as possibilidades de aplicação de penas diversas da prisão e da Lei 11.343, de 2006, que tratou, entre outras questões, das punições aplicáveis ao porte de drogas para uso pessoal e ao tráfico de drogas. Com essa análise, buscou-se colocar em evidência as concepções sobre crime e punição e os modos como tais concepções foram mobilizadas em diferentes momentos para a produção de alternativas às penas privativas de liberdade.

\section{A emergência de alternativas penais à prisão no Brasil}

A Lei $n^{\circ} 7.209 / 84$, que reformou a parte geral do Código Penal, introduziu a possibilidade de substituição da pena privativa de liberdade aplicada aos crimes culposos e daquelas de até um ano aplicadas aos crimes dolosos pelas penas restritivas de direitos que estabelecia. Naquele momento, as penas restritivas de direitos eram a prestação de serviços à comunidade, as interdições temporárias de direitos e a limitação de fim de semana. Além disso, tornou-se possível substituir a pena privativa de liberdade aplicada, não superior a seis meses, por Rev. Polis e Psique, 2013;3(3):165-188 multa. A lei referida ampliou também as possibilidades de suspensão condicional da pena e integrou este instituto às penas restritivas de direitos criadas.

Posteriormente, em 1998, duas leis modificaram as penas restritivas de direitos no Brasil e as suas possibilidades de aplicação. Inicialmente, em fevereiro daquele ano, a Lei $n^{0} 9.605$ estabeleceu hipóteses diferenciadas de aplicação de penas restritivas de direitos quando se tratasse de crimes ambientais. Além da prestação de serviços à comunidade e da interdição temporária de direitos, previstas para os demais crimes, a Lei $\mathrm{n}^{\circ} 9.605$ incluiu como penas restritivas de direitos aplicáveis aos autores de infrações penais ambientais a suspensão parcial ou total de atividades, a prestação pecuniária e o recolhimento domiciliar e, nos casos em que o agente fosse pessoa jurídica, a suspensão parcial ou total de atividades, a interdição temporária de estabelecimento, obra ou atividade e a proibição de contratar com o Poder Público, bem como dele obter subsídios, subvenções ou doações. O limite da pena privativa de liberdade aplicada passível de substituição nesses casos, por sua vez, passou de um para quatro anos.

Em novembro de 1998, a Lei ${ }^{\circ}$ 9.714 alterou as previsões acerca das penas restritivas de direitos para os demais crimes, possibilitando que penas privativas de liberdade inferiores a quatro anos fossem substi- 
tuídas por penas restritivas de direitos, ressalvados os casos de crimes cometidos com violência ou grave ameaça. Ainda, foram incluídas no rol de penas restritivas de direitos a prestação pecuniária e a perda de bens e valores, além da proibição de frequentar determinados lugares como modalidade de interdição de direitos. Apesar de constarem na lei aprovada, a pena de recolhimento domiciliar e a admoestação verbal foram vetadas pelo Executivo. Em 2006, no entanto, a admoestação verbal passou a compor o rol de penas diversas da prisão. A Lei no 11.343 estabeleceu que as penas aplicadas àqueles que portassem ou cultivassem drogas ilícitas para uso próprio seriam a advertência sobre os efeitos das drogas, prestação de serviços à comunidade e medida educativa de comparecimento a programa ou curso educativo. Em caso de recusa no cumprimento dessas penas pelo condenado, não há previsão de pena privativa de liberdade, cabendo ao juiz admoestá-lo verbalmente ou lhe aplicar multa.

A expansão das estruturas estatais direcionadas à aplicação dessas penas diversas da prisão no Brasil ocorre a partir de 2000, período em que também ocorre a expansão do número de indivíduos submetidos a penas ou medidas alternativas, os quais, em 2008, superaram o número de pessoas submetidas à prisão de forma cautelar ou condenadas, segundo dados do Mi- nistério da Justiça ${ }^{1}$. Uma das razões apontadas para essa mudança no cenário nacional em relação às penas e medidas alternativas é o estabelecimento, pelo Governo Federal, de uma "Política Nacional de Penas e Medidas Alternativas" em 2000 (Barreto, 2010).

Colocando esses acontecimentos dessa forma, o que vemos é o desenvolvimento gradual e contínuo de uma política penal direcionada a práticas punitivas estatais diversas do encarceramento para reação às condutas qualificadas como crimes. No entanto, análises sobre a política criminal brasileira no período apontam o seu desenvolvimento em diversas direções. Essa tendência de produção de alternativas à pena de prisão e ao processo penal ocorreu concomitantemente com tendências de agravamento das penas e da expansão da criminalização de condutas (Azevedo, 2004; Campos, 2010; Pinto, 2006). A pesquisa desenvolvida por Santos (2011) apontou que foram criadas 869 novas hipóteses de condutas qualificadas como crimes a partir de 1988. Em 760 delas é possível a aplicação de alguma forma de alternativa penal à prisão.

Nas conclusões da pesquisa "Levantamento Nacional sobre Execução de Penas Alternativas", realizada no Brasil entre dezembro de 2004 e janeiro de 2006 pelo Instituto Latino Americano das Nações Unidas para Prevenção do Delito e Tratamento do Delinquente (Ilanud/Brasil), é afirmado que 
a pena alternativa, tal como prevista na legislação brasileira e aplicada pelo sistema de justiça, não implicou numa diminuição do número de pessoas presas, pois o perfil do indivíduo submetido a pena restritiva de direito, em especial se levado em conta o tipo de delito, é diverso daquele que compõe a população carcerária. Os indivíduos condenados à pena privativa de liberdade $\mathrm{e}$ que têm sua pena substituída por uma pena alternativa não cumpririam suas penas presos, diante da preexistência de outros institutos jurídicos que evitariam sua prisão (Ilanud, 2006).

Analisando conjuntamente as análises apresentadas pela pesquisa de Santos (2011) e do Ilanud (2006), parece plausível a hipótese de uma relação entre a expansão da aplicação de penas e medidas diversas das privativas de liberdade e a criminalização de novas condutas que ocorreu no mesmo período. Assim, mesmo que as alternativas penais não tenham sido direcionadas às condutas tradicionalmente punidas com penas privativas de liberdade, e, portanto, não tenham implicado em uma redução da utilização da pena de prisão, a expansão do número de sujeitos submetidos a alternativas penais também teria sido possível graças à criação de novas hipóteses de crimes aos quais, na sua maioria, é possível aplicar alguma forma de pena ou medida diversa da prisão. Ainda que essa seja uma hipótese que demanda maior análise para confirmação, ela vai ao encontro das conclusões de Campos (2010), apontando que essa tendência de política criminal de produção de alternativas à prisão e ao processo penal coexiste, sem implicar necessariamente relações de oposição, com as tendências de agravamento das penas e criminalização de novas condutas, articulando-se umas às outras.

\section{Uma análise tática das alternativas penais à prisão e seus discursos}

As alternativas penais precisam ser analisadas enquanto instrumentos em uma luta política, elementos inseridos em jogos de força, atravessados por relações de poder-saber, que se integram a dispositivos jurídico-legais, disciplinares e de segurança. São técnicas que tem sua especificidade entre outros processos de poder, devendo o poder ser compreendido como uma estratégia, cujos efeitos de dominação atribuem-se a manobras, táticas, funcionamentos (Foucault, 1975/2004). Ao mesmo tempo em que possibilitam a resistência a uma certa configuração do poder punitivo, as alternativas penais somente se constituem enquanto possibilidade de resistência por não se encontrarem "fora" da configuração de poder a que se contrapõem, mas justamente num dos pontos em que ele é exercido e que por aí mesmo pode ser reconduzido. 
Como proceder essa análise das alternativas penais? Os agentes políticos e agências governamentais envolvidos na política criminal brasileira, a partir de 1984, produziram diversos documentos oficiais que abordam alternativas penais à pena de prisão: textos de leis, de resoluções, de políticas elaboradas sobre o tema, bem como exposições de motivos, justificativas de projetos de lei, mensagens de veto, entre outros. Em tais documentos, encontram-se discursos não só sobre essas modalidades de sanção, mas sobre a prisão, sobre a criminalidade e sobre os sujeitos que as práticas da justiça criminal tinham por objetivo. Esses documentos podem ser tomados enquanto uma produção histórica, política, onde a linguagem neles presente é também constitutiva das práticas a que eles se referem (Fischer, 2001).

Os discursos implicados na construção das alternativas penais à pena de prisão precisam ser analisados enquanto um "jogo estratégico" (Foucault, 1973/2008, p. 9). Nesses discursos encontrar-se-ia uma disputa em que diferentes concepções - de sujeito, de responsabilidade, de relações entre as pessoas - se enfrentam, produzindo vitórias, derrotas e alianças temporárias, cujos resultados se refletem nas diferentes maneiras de denominar o que constitui a "criminalidade" e agir sobre ela. Uma mudança no discurso sobre o lugar da prisão no controle da cri- minalidade aponta transformações em uma determinada prática e na sua articulação com práticas conexas. Em razão de suas características, de suas condições de emergência, o discurso coloca desde a sua existência a questão do poder, e não apenas nas suas possibilidades de utilização, constituindo-se enquanto um objeto de uma luta política (Foucault, 1969/2009).

Entendemos que a compreensão acerca dos diferentes discursos presentes na produção de alternativas penais à pena de prisão no Brasil, e sua articulação com os contextos em que emergem, tem o potencial de dar visibilidade à(s) racionalidade(s) que orientam as práticas dessas alternativas. É somente a partir da crítica dessa(s) racionalidade(s) que poderemos decidir de que modo devemos nos posicionar em relação a ela(s). Não se trata de dizer uma "verdade" muda, oculta nas políticas de alternativas penais à prisão, mas de, a partir da reflexão sobre elas, forjar instrumentos de luta contra certas formas de poder implicadas nos modos como pensamos e atuamos em relação ao crime, constituindo a pesquisa acadêmica enquanto uma prática política.

Os documentos analisados foram aqueles relacionados ao processo de proposição, tramitação, aprovação e sanção das Leis $n^{\circ}$ s 7.209/1984, 9.605/1998, 9.714/1998 e 11.343/2006, quais sejam: os projetos de lei e suas justificativas, os pare- 
ceres das comissões da Câmara dos Deputados e do Senado Federal que os analisaram, as emendas apresentadas aos projetos e suas justificativas e os debates realizados nas casas do Congresso Nacional. A obtenção do material foi feita por meio eletrônico, mediante consulta aos sites da Câmara dos Deputados, do Senado Federal e da Presidência da República.

Com o auxílio do software de pesquisa qualitativa NVivo, versão 10, a análise dos discursos presentes nesses documentos foi realizada a partir dos seguintes indicadores: "visões" (como a prisão e as alternativas propostas a ela são enunciadas nesses discursos?); "sujeitos" (de que modo são objetivados os sujeitos destinatários dessas diferentes práticas punitivas estatais?); “justificativas" (quais os motivos para implementar as alternativas penais e quais as razões para manter a prisão?); "efeitos” (quais as funções ou efeitos esperados pela adoção de uma ou outra forma de punição?); "aplicação" (em que situações se deve aplicar as alternativas penais e em que situações se deve aplicar a prisão?); "posicionamento" (qual a relação que há ou que deveria haver entre a prisão e as alternativas propostas a ela?). Cada um desses indicadores foi utilizado como um "nó" de análise no NVivo. A partir da categorização dos documentos e indicação dos nós de análise, buscou-se paRev. Polis e Psique, 2013; 3(3):165-188 drões entre os conteúdos referenciados em cada nó e entre nós diferentes.

\section{Produzindo alternativas: da (des) necessidade da prisão à otimização da punição}

A reforma da parte geral do Código Penal, em 1984, produzida pela Lei 7.209/1984, insere-se em uma perspectiva de modernização da Justiça Criminal e de reação do Estado à criminalidade. $\mathrm{O}$ anteprojeto de reforma da parte geral, após algumas modificações, transformou-se no Projeto de Lei n. 1.656 de 1983. Na exposição de motivos do projeto em questão, o então Ministro da Justiça, Ibrahim Abi-Ackel, assim situava a crise do modelo penitenciário centrado na pena privativa de liberdade:

As críticas que em todos os países se têm feito à pena privativa da liberdade fundamentamse em fatos de crescente importância social, tais como o tipo de tratamento penal freqüentemente inadequado e quase sempre pernicioso, a inutilidade dos métodos até agora empregados no tratamento de delinquentes habituais e multi-reincidentes, os elevados custos da construção e manutenção dos estabelecimentos penais, as conseqüências maléficas para os infratores primários, ocasionais ou responsáveis por delitos de pequena significação, sujeitos, na intimidade do cárcere, a sevícias, corrupção e perda paulatina da aptidão para trabalho (Diário do Congresso Nacional, 1983, $1^{\circ}$ de 
julho, p. 16).

Apesar dessas constatações, a pena privativa de liberdade não é problematizada como algo a ser eliminado, mas cujo uso precisa ser restrito. Uma das justificativas mobilizadas para isso é a "proteção da sociedade", o que demandaria impedir o efeito de indução à criminalidade atribuído à prisão em relação aos sujeitos a ela submetidos, como exposto pelo Ministro da Justiça:

Uma política criminal orientada no sentido de proteger a sociedade terá de restringir a pena privativa da liberdade aos casos de reconhecida necessidade, como meio eficaz de impedir a ação criminógena cada vez maior do cárcere. Esta filosofia importa obviamente na busca de sanções outras para delinqüentes sem periculosidade ou crimes menos graves. Não se trata de combater ou condenar a pena privativa da liberdade como posta penal básica ao delito. Tal como no Brasil, a pena de prisão se encontra no âmago dos sistemas penais de todo o mundo. O que por ora se discute é a sua limitação aos casos de reconhecida necessidade (Diário do Congresso Nacional, 1983, $1^{\circ}$ de julho, p. 16).

Essa referência à limitação da utilização da prisão a "casos de reconhecida necessidade" é reiterada pelo deputado federal Nilson Gibson (PMDB/PE)², relator do parecer emitido na Comissão de Constituição e Justiça da Câmara dos Deputados acerca do projeto 1.656/83 (Diário do Congresso Nacional, 1983, $1^{\circ}$ de dezembro, p. 13663). Da mesma forma, está presente no parecer da comissão equivalente no Senado Federal, em que foi relator o senador Odacir Soares (PDS/RO) (Diário do Congresso Nacional, 1984, 16 de junho, p. 2032). Quais são esses "casos de reconhecida necessidade"?

Pelas referências feitas na exposição de motivos do Projeto de Lei 1.656/83 pelo Ministro Ibrahim Abi-Ackel, tratam-se dos agentes "[...] dotados de acentuada periculosidade" (Diário do Congresso Nacional, 1983, $1^{\text {o }}$ de julho, p. 19), ou, como referido pelo senador Odacir Soares no parecer da Comissão de Constituição e Justiça do Senado acerca do projeto em questão, trata-se do "[...] delinquente perigoso, que intranquiliza presentemente os centros urbanos [...]" (Diário do Congresso Nacional, 1984, 16 de junho, p. 2031). As novas modalidades de penas diversas da prisão, por sua vez, destinam-se, como referido pelo Ministro Abi-Ackel, aos "delinquentes sem periculosidade", aos "infratores primários, ocasionais, ou responsáveis por delitos de pequena significação", aos "infratores que não ponham em risco a segurança da sociedade" (Diário do Congresso Nacional, 1983, $1^{\mathrm{o}}$ de julho, p. 16-7). Assim, a reforma da parte geral do Código Penal se coloca um duplo propósito: “[...] aperfeiçoar a pena de 
prisão, quando necessária, e de substituí-la, quando aconselhável, por formas diversas de sanção criminal, dotadas de eficiente poder corretivo [...]" (Diário do Congresso Nacional, 1983, $1^{\circ}$ de julho, p. 17).

Nesse momento de emergência das penas restritivas de direito, essa é a referência mais direta feita aos efeitos que se espera serem produzidos por tais penas nos sujeitos a elas submetidos. De toda forma, o objetivo de buscar produzir uma modificação no sujeito punido, traduzida na forma de "tratamento" e "ressocialização", está presente de forma geral: “[...] o objetivo é restringir-se a pena privativa de liberdade aos casos de reconhecida necessidade e, mesmo assim, não se descurando do objetivo principal da pena que é o da ressocialização", como afirma o deputado Nilson Gibson (Diário do Congresso Nacional, 1983, $1^{\circ}$ de dezembro, p. 13674). A proposta de criação de uma hipótese de suspensão condicional da pena para maiores de 70 anos foi assim justificada na emenda apresentada pelo deputado Raymundo Ásfora (PMDB/ PB) ao projeto de lei n. 1.656/1983:

\begin{abstract}
A emenda propõe que seja concedida também a suspensão da pena privativa de liberdade até quatro anos, quando o condenado for maior de 70 anos de idade.
\end{abstract}

Justifica-se a pretensão desse tratamento excepcional ao maior de 70 anos, pela razão mesma de sua idade, pois, essa altura da vida, não será na prisão que venha a reeducar-se (Diário do Congresso Nacional, 1983, $1^{\circ}$ de dezembro, p. 13659).

Se, por um lado, argumenta-se que a prisão enquanto pena deve ser destinada a esses sujeitos ditos perigosos, será a prisão também, nesse momento, que será vista como espaço e meio através do qual se intervirá nesse sujeito. Assim, pela lógica inversa, justifica-se a utilização de alternativas à prisão não só quando se entende que essa intervenção é desnecessária, pois não haveria periculosidade, mas também quando há poucas chances de se obter a modificação esperada do sujeito. As alternativas à prisão, então, não vem para tomar o lugar de principal reação ao crime, mas para permitir uma maior "personalização" das penas impostas pelo Estado conforme o sujeito condenado, como apontado na exposição de motivos do projeto de lei n. 1.656/83:

Sob a mesma fundamentação doutrinária do Código vigente, o projeto busca assegurar a individualização da pena sob critérios mais abrangentes e precisos. Transcende-se, assim o sentido individualizador do Código vigente, restrito à fixação da quantidade da pena, dentro de limites estabelecidos, para oferecer ao arbitrium iudicis variada gama de opções, que em deter minadas circunstâncias pode envolver o tipo da sanção a ser aplicada (Diário do Congresso Nacional, 1983, $1^{\circ}$ de julho, p. 18). 
Apesar de no Projeto de Lei $n^{\circ} 1.656$ de 1983 a possibilidade de substituição por penas restritivas de direito estar vinculada ao fato de tratar-se de crime culposo, ou então, nos crimes dolosos, à quantidade de pena privativa de liberdade aplicada, o arbítrio do juiz possui papel central na decisão sobre a substituição ou não. Em algumas de suas modalidades, as alternativas à prisão somente são aplicáveis quando as “[...] condições subjetivas do agente forem inteiramente favoráveis: antecedentes irretocáveis, boa índole e personalidade" (Diário do Congresso Nacional, 1983, $1^{\circ}$ de julho, p. 20). Como destacou o Ministro Ibrahim Abi-Ackel:

Essas penas privativas de direitos, em sua tríplice concepção, aplicam-se aos delitos dolosos cuja pena, concretamente aplicada, seja inferior a um ano e aos delitos culposos de modo geral, resguardando-se, em ambas as hipóteses, o prudente arbítrio do juiz. A culpabilidade, os antecedentes, a conduta social e a personalidade do agente, bem como os motivos e circunstâncias do crime, é que darão a medida de conveniência da substituição (Diário do Congresso Nacional,

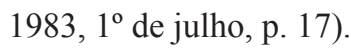

A expansão da aplicação de penas e medidas diversas da prisão ocorreu após o ano 2000. A baixa aplicação inicial, em uma leitura apressada, poderia ser atribuída a um erro de planejamento ou implementação. No entanto, a leitura da exposição de motivos do Projeto de Lei n. 1.656/84 permite perceber que esse era não só um resultado esperado, mas desejado. A expectativa de que as penas restritivas de direitos teriam baixa aplicação, assim como a suspensão condicional da pena havia tido até aquele momento, dava condições para a implementação dessas novas modalidades de penas. Nas palavras de Abi-Ackel:

\footnotetext{
Por esta razão, o projeto situa as novas penas na faixa ora reservada ao instituto da suspensão condicional da pena, com significativa ampliação para os crimes culposos. Aprovada a experiência, fácil será, no futuro, estendê-la a novas hipóteses, por via de pequenas modificações no texto. Nenhum prejuízo, porém, advirá da inovação introduzida, já que o instituto da suspensão condicional da pena, tal como já vem sendo aplicado com base no Código de 1940, é um quase nada jurídico (Diário do Congresso Nacional, 1983, $1^{\circ}$ de julho, p. 17).
}

A relação entre a prisão e as novas penas propostas é estabelecida de tal forma que, se as penas restritivas são instituídas para evitar a aplicação da pena de prisão a partir da sua substituição, é a possibilidade do retorno dessa pena de prisão durante o cumprimento da pena restritiva que dá o caráter coativo a essa nova modalidade de pu- 
nição (Diário do Congresso Nacional, 1983, $1^{\mathrm{o}}$ de julho, p. 17). Assim, ainda que caracterizadas como "penas", não são compreendidas como portadoras de força coercitiva autônoma, demandando a sua vinculação à pena privativa de liberdade.

A Lei 9.714 de 1998, que ampliou as possibilidades de aplicação das penas restritivas de direitos, teve origem no Projeto de Lei n. 2.684 de 1996, proposto pelo então Presidente da República Fernando Henrique Cardoso (PSDB/SP). Permanece o discurso que constata que as penas privativas de liberdade não cumprem a função esperada, mas são a punição a ser adotada frente a determinados sujeitos. Na exposição de motivos do projeto em questão, o Ministro da Justiça à época, Nelson Jobim, assim coloca o problema:

A prisão não vem cumprindo o principal objetivo da pena, que é reintegrar o condenado ao convívio social, de modo que não volte a delinqüir.

4. Mas, se infelizmente não temos, ainda, condições de suprimir por inteiro a pena privativa de liberdade, caminhamos a passos cada vez mais largos para o entendimento de que a prisão deve ser reservada para agentes de crimes graves e cuja periculosidade recomende seu isolamento do seio social. Para os crimes de menor gravidade, a melhor solução consiste em impor restrições aos direitos do condenado, mas sem retirá-lo do convívio social. Sua conduta criminosa não ficará impune, cumprindo, assim, os desígnios da prevenção especial e da prevenção geral. Mas a execução da pena não o estigmatizará de forma tão brutal como a prisão, antes permitirá, de forma bem mais rápida e efetiva, sua integração social. Nessa linha de pensamento é que se propõe, no projeto, a ampliação das alternativas à pena de prisão. [...]

18. Estas, Senhor Presidente, as normas que integram a presente propositura e que, acredito, vêm ao encontro do desiderato principal da pena - a reinserção do condenado na sociedade (Diário da Câmara dos Deputados, 1997, 20 de fevereiro, p. 4487).

Aqui, se podemos perceber a presença ainda do discurso que afirma a possibilidade de ação sobre sujeito condenado e modificação de sua relação com a sociedade a partir da pena, expressa pela ideia de reintegração social, há uma modificação no lugar ocupado pelas penas não privativas de liberdade. A prisão não aparece vinculada à ideia de "tratamento penal", como no período da reforma da parte geral do Código Penal, mas de isolamento de sujeitos em razão de sua periculosidade. As estratégias que de fato possibilitarão a "integração social" do condenado, bem como a prevenção da ocorrência de novos crimes, são as alter- 
nativas penais à prisão, cuja ampliação se propunha. Como afirmou o senador Ramez Tebet (PMDB/MS), durante a discussão do projeto no Senado Federal, “[...] os nossos presídios superlotados não recuperam o criminoso. É preciso adotar novas fórmulas para recuperar o criminoso e diminuir a quantidade de pessoas recolhidas nos presídios" (Diário do Senado Federal, 1998, 25 de março, p. 4935).

Apesar disso, a pena privativa de liberdade ainda é mobilizada como sendo a reação a ser adotada pelo Estado para determinados sujeitos. Os destinatários da prisão seriam os "agentes de crimes graves e cuja periculosidade recomende seu isolamento do seio social" (Diário do Senado Federal, 1998, 25 de março, p. 4935), aqueles “[...] que têm não condições de se manter em liberdade porque incapazes, pela periculosidade, de conviver em sociedade" (Diário da Câmara dos Deputados, 1997, 24 de julho, p. 21321), ou, em uma descrição que utiliza quase as mesmas palavras dos incisos II e III do art. 44 do Código Penal, “[...] o condenado tido por criminoso habitual ou reincidente, cuja culpabilidade, antecedentes, conduta social, personalidade, motivo e circunstâncias não indicarem a conveniência da substituição (Diário da Câmara dos Deputados, 1997, 24 de julho, p. 21199). Assim, evita-se “[...] o recolhimento à prisão de condenados que por ausência de peRev. Polis e Psique, 2013;3(3):165-188 riculosidade não constituem ameaça à segurança individual ou coletiva" (Diário da Câmara dos Deputados, 1997, 24 de julho, p. 21199).

$\mathrm{Na}$ tramitação do projeto 2.684 de 1996, emergem discursos acerca das alternativas à prisão mais focados em questões gerenciais e atuariais. No parecer da Comissão de Constituição e Justiça na Câmara dos Deputados, assim se manifestou o relator, então deputado federal Ibrahim Abi-Ackel (PPB/MG), acerca da pena de recolhimento domiciliar:

O "recolhimento domiciliar" se cumpre mediante trabalho, sem vigilância, frequência a curso ou exercício de outra atividade, mediante autorização, e permanência, nos dias ou horários de folga, em residência ou qualquer local destinado à moradia habitual do condenado. Com esta nova pena substitutiva resolve-se o sério problema da falta da "casa de albergado", prevista no Código para o cumprimento do regime aberto [...] (Diário da Câmara dos Deputados, 1997, 24 de julho, p. 21199)

A instituição de uma nova modalidade de pena, assim, aparece como solução para a falta de investimento público na construção das estruturas adequadas exigidas pela Lei de Execução Penal. A ampliação das possibilidades de aplicação de alternativas à prisão também é vista como possibilidade de redução da superlotação 
nas prisões, "sem prejuízo para a sociedade", como destacado pelo deputado Ibrahim Abi-Ackel na discussão do projeto na Câmara (Diário da Câmara dos Deputados, 1997, 24 de julho, p. 21322). Isso também é destacado pelo deputado Féu Rosa (PSDB/ ES):

Há muito tempo estamos batalhando esse item como um dos que mais atenuam a crise carcerária no Brasil. [...] A lotação de nossos presídios não pode pôr em xeque a tranqüilidade da sociedade. Sabemos pelas estatísticas que mais de $25 \%$ dos crimes no Brasil são praticados por detentos que fugiram da cadeia. (Diário da Câmara dos Deputados, 1997, 24 de julho, p. 21323)

A aplicação de penas restritivas de direito, em vez de penas privativas de liberdade, é vinculada às possibilidades de redução de custos no sistema penitenciário. Como sustentou o deputado federal, Fernando Gabeira (PV/RJ), durante a discussão do projeto 2.684/96:

Neste momento, também desejo destacar a importância do trabalho da socióloga Julita Lemgruber ao explicar a importância das penas alternativas. A socióloga mostra que, muitas vezes no Brasil, se uma pessoa roubar uma fralda, ou algum objeto de pequeno valor, será mantida na cadeia. E a sociedade gasta o equivalente a cinco salários mínimos por mês para mantê-la.
Simultâneamente, milhares de mandados de prisão não são executados por falta de local nas penitenciárias. [...]

Estamos dando um passo para melhorar a vida de milhares de pessoas no Brasil. Mais do que isso: fazer com que o contribuinte brasileiro gaste menos dinheiro nessas penas irracionais que continuam a existir em nosso País. (Diário da Câmara dos Deputados, 1997, 24 de julho, p. 21320)

Esse argumento coloca em relação não só os diversos custos da punição conforme as penas adotadas, mas também o custo da punição diante do custo do dano causado por alguns crimes punidos com penas privativas de liberdade. Ainda, atribui à falta de vagas nas penitenciárias o não cumprimento de mandados de prisão. O senador Romeu Tuma (PFL/SP), durante a discussão do projeto de lei assim se manifestou:

Com a restrição dos direitos civis, individuais, o cidadão que praticou um crime sem violência, sem dúvida nenhuma, sentirá que está sendo punido pelo delito. No entanto, prestando serviço à sociedade, poderá a ela se reincorporar na medida em que termine de cumprir a sua pena. [...]

Muitas vezes, o juiz se sente quase que impelido a não aplicar uma pena restritiva de liberdade porque sabe que, se o fizer, aquele que tenha aplicado o delito pela primeira vez poderá não ser recuperado e ainda sairá 
da cadeia com um terrível know-how e com espírito de vingança contra a sociedade. Poderá, em conseqüência, praticar outros delitos com muito mais gravidade. (Diário do Senado Federal, 1998, 25 de março, p. 4936).

A aplicação de alternativas à prisão, nesse argumento, representa uma possibilidade real de punição para o sujeito a ela submetido, mas também uma solução para o juiz que considere os riscos decorrentes da aplicação de uma pena privativa de liberdade e seus efeitos. Por outro lado, as penas diversas da prisão, se não fiscalizadas, também podem elas mesmas representarem impunidade, como sustentado pelo deputado federal Hélio Bicudo (PT/SP) na discussão do PL 2.684/96 na Câmara:

Sr. Presidente, peço aos Governos Estaduais e ao Presidente da República para que dêem aos juízes a infra-estrutura necessária à fiscalização do cumprimento de penas alternativas, porque sem ela ingressaremos no campo da impunidade. Queremos alternativas, sim, mas com fiscalização. (Diário da Câmara dos Deputados, 1997, 24 de julho, p. 21320)

A questão do quanto as alternativas à prisão propostas no projeto de lei 2.684/96 representam ou não uma pena é o que será utilizado como argumento pelo Presidente Fernando Henrique para vetar as penas de recolhimento domiciliar e de advertência quando da sanção da Lei 9.714 em 25 de novembro de 1998. Note-se que tais penas já estavam presentes no projeto de lei original encaminhado por esse mesmo Presidente. Na Mensagem de Veto no 1.447 de 1998, a justificativa para os vetos foi a seguinte:

\begin{abstract}
A figura do "recolhimento domiciliar", conforme a concebe o Projeto, não contém, na essência, o mínimo necessário de força punitiva, afigurando-se totalmente desprovida da capacidade de prevenir nova prática delituosa. Por isto, carente do indispensável substrato coercitivo, reputouse contrária ao interesse público a norma do Projeto que a institui como pena alternativa. $[\ldots]$
\end{abstract}

Em paralelismo com o recolhimento domiciliar, e pelas mesmas razões, o $\S 10$ do art. 44, que permite a substituição de condenação a pena privativa de liberdade inferior a seis meses por advertência, também institui norma contrária ao interesse público, porque a admoestação verbal, por sua singeleza, igualmente carece do indispensável substrato coercitivo, necessário para operar, no grau mínimo exigido pela jurisdição penal, como sanção alternativa à pena objeto da condenação. (Diário Oficial da União, 1998, 26 de novembro, p. 37)

Apesar de vetado nessa ocasião, o recolhimento domiciliar, como modalidade de pena alternativa à privação de liberda- 
de, já fazia parte do rol de penas aplicáveis no Brasil, por conta de sua inclusão na Lei 9.605, sancionada em fevereiro de 1998. A Lei 9.605, que tratou das infrações administrativas e dos crimes relacionados ao meio ambiente, teve origem em dois projetos de lei: o PL 1.164, de 1991, proposto pelo Presidente da República Fernando Collor (PRN/AL), ao qual foi apensado o PL 1.658, de 1991, proposto pelo deputado federal Cardoso Alves (PTB/SP). Nenhum desses projetos propunha a aplicação de penas restritivas de direito específicas aos crimes ambientais.

Foi somente no parecer da Comissão de Assuntos Sociais no Senado, de autoria da senadora Marina Silva (PT/AC), que apareceu a primeira proposta de penas restritivas de direitos específicas aos crimes ambientais: prestação de serviços à entidade ambiental, cassação da autorização ou licença concedida pela autoridade competente e suspensão das atividades (Diário do Senado Federal, 1997, 17 de janeiro, p. 2502). A pena de recolhimento domiciliar, no entanto, somente foi introduzida por meio de um substitutivo oferecido em plenário quando da discussão do projeto de lei no Senado, por iniciativa do senador Joel de Hollanda (PFL/PE), justificando sua proposição por estar "[...] está de acordo com a política penitenciária nacional, em relação a dosimetria das penas, com ênfase na possibilidade da aplicação de penas Rev. Polis e Psique, 2013;3(3):165-188 alternativas a prisão e progressão do regime de cumprimento das penas privativas de liberdade" (Diário do Senado Federal, 1997, 28 de janeiro, p. 3171).

O debate sobre a punição dos crimes ambientais esteve marcado por um discurso que fundamentava a necessidade de mudança na legislação em razão das penas severas existentes na legislação até então para alguns casos. Esse rigor foi destacado na análise dos projetos de lei pela Comissão de Constituição e Justiça da Câmara (Diário do Congresso Nacional, 1995, 21 de janeiro, p. 1171), quanto pela comissão semelhante no Senado, quando o senador Lúcio Alcântara assim se manifestou em seu parecer:

As distorções da Lei de Proteção à Fauna deram origem a uma série de dificuldades de ordem jurídica e a graves injustiças quando de sua aplicação. A imprensa noticia, com freqüência, exemplos de indivíduos completamente excluídos do sistema social brasileiro que vêem agravado o seu grau de exclusão pela cominação de penas absurdamente desproporcionais aos delitos cometidos. Há relatos de juízes, inclusive, que lamentam ter a obrigação jurídica de cumprir uma lei que se revela inadequada ao ordenamento legal nacional e incongruente com a realidade sócio-econômica do País (Diário do Senado Federal, 1997, 15 de janeiro, p. 2166)

Na justificativa do PL 1.658, o deputado Cardoso Alves fazia referência ao "po- 
bre passarinheiro" punido por crime contra a fauna:

Caiu, assim, aquele pobre passarinheiro, nas malhas da lei, nas agruras de um cárcere. Levado para a Delegacia de Polícia, encaminhado, depois, certamente, com exagerados cuidados, para a Superintendência Regional da Polícia Federal, incurso o pobre homem em crime contra a fauna, o que vale dizer: crime contra o Estado!

Trata-se, assim, de mais uma vítima dos ecomaníacos, que sacrificam o homem na defesa da ecologia, se necessário.

A lei que dispõe sobre a proteção à fauna, modificada pela legislação inspirada pelo Senador José Fragelli, com vistas à proteção dos jacarés, frente a seus implacáveis peleteiros e contra a predatória passarinhagem silvestre, tornou-se extremamente injusta e absurda, carecendo de nossa parte - legisladores - a limitação de seus excessos e urgente e inadiável revisão, que ora submetemos ao exame de nossa Casa (Diário do Congresso Nacional, 1995, 21 de janeiro, p. 1159).

É interessante que essa objetivação como "vítima" (no caso, de uma legislação compreendida como grave demais) ao fazer referência ao sujeito que pratica o ato criminalizado, aparece também nos discursos presentes na tramitação do projeto de lei que resultou na Lei 11.343 de 2006, que, entre outras questões, estabeleceu que a punição de condutas relacionadas ao consumo de drogas seria feita exclusivamente por penas diversas da prisão. É na Lei 11.343 que a pena de advertência, vetada pelo Presidente Fernando Henrique quando da sanção da lei que ampliou a aplicação das alternativas penais à prisão para os crimes em geral, passará a fazer parte do rol de alternativas à prisão aplicáveis no Brasil.

O usuário de drogas é objetivado como "vítima das drogas" (Diário da Câmara dos Deputados, 2004, 12 de fevereiro, p. 5445) na fala do deputado Antônio Carlos Biscaia (PT/RJ), e também na do deputado Dimas Ramalho (PPS/SP):

\begin{abstract}
$\mathrm{Na}$ minha vida profissional, como membro do Ministério Publico do Estado de São Paulo, muitas vezes me vi extremamente incomodado por precisar denunciar um jovem usuário, um estudante, e ter de mandá-lo à prisão, quando na realidade o jovem é muito mais uma vítima do que um praticante de ato criminoso que mereça prisão. [...]
\end{abstract}

Esse projeto, portanto, avança, pois diferencia o usuário do traficante e concede a um e outro tratamento diferente. Ainda que mantenha a classificação de criminoso para o portador de droga, o tratamento que lhe dá é diferente, é pedagógico, com pena de prestação de serviços à comunidade, o que dará à família e à sociedade uma chance de ajudarem o dependente a se recuperar e 
voltar a trabalhar. Por outro lado, é tratada com maior rigidez a situação do traficante, com previsão de penas mais duras.

Sr. Presidente, esta Casa está dando apoio a quem dele mais necessita, ajudando a acabar com a hipocrisia que às vezes se comete neste País, onde mães, esposas, companheiras, jovens estudantes, trabalhadores etc, são colocados atrás das grades, superlotando os presídios, porque são viciados. Essas pessoas não deveriam ser presas. [...]

Ora, que perigo pode oferecer à sociedade esse jovem? (Diário da Câmara dos Deputados, 2004, 12 de fevereiro, p. 5447)

Essa necessidade de diferenciação entre o usuário de drogas e o traficante é reiterada em diversos documentos (por exemplo: Diário da Câmara dos Deputados, 2004, 12 de fevereiro, p. 5402; Diário do Senado Federal, 2006, 06 de julho, p. 22778; Diário Oficial da União, 2006, 24 de agosto, p. 7), justificando a adoção de diferentes estratégias pelo Estado. Assim, ao usuário devem ser destinadas medidas de caráter educativo, inserção no âmbito da saúde pública, buscando a prevenção, atenção e a reinserção social de usuários e dependentes de drogas. Em relação ao traficante, por outro lado, precisa ser considerado o "clamor da sociedade brasileira", conforme o relator do projeto de lei na Comissão de Constituição e
Justiça da Câmara, deputado Paulo Pimenta (PT/RS):

Nesse sentido, procuramos, no Substitutivo, separar usuário ou dependente do traficante. Para os primeiros, formulamos uma Política que busca inseri-los no âmbito da saúde pública. Para os segundos, atendendo ao clamor da sociedade brasileira, mantivemos as medidas de caráter repressivo, melhorando, no entanto, a redação de alguns dispositivos que não estavam de acordo com o sistema de penas brasileiro (Diário da Câmara dos Deputados, 2004, 12 de fevereiro, p. 5402).

Novamente aparecem questões sobre o custo das penas até então adotadas e os resultados obtidos com elas, numa perspectiva gerencialista - a prisão de usuários, além de não trazer nenhum benefício, pois impede que recebam tratamento eficaz, ainda os faz conviverem com agentes de crimes muito mais graves (Diário da Câmara dos Deputados, 2004, 12 de fevereiro, p. 5403). Esse cálculo de custos fica evidente nesse trecho da fala do deputado federal Givaldo Carimbão (PSB/AL) durante a discussão do projeto de lei na Câmara dos Deputados:

Um preso custa hoje à Nação em torno de 1.200 reais por mês. Como passa em média 10 anos, ou 120 meses, na cadeia, fazendo a multiplicação, constatamos que um preso, ao cabo de sua pena, terá custado 
cerca de 150 mil reais à Nação. E o mais grave é que $99,9 \%$ deles saem piores do que quando entraram. Por outro lado, há no País centenas de instituições que recuperam não traficantes, mas usuários de drogas, com índices positivos em torno de $80 \%$, a um custo. de 400 a 500 reais por mês, ao longo de 1 ano. O Brasil vai gastar 150 mil reais com um homem, mas não poderia gastar 5 mil reais para recuperá-lo? O usuário, que pode ser recuperado, vai para a cadeia junto com marginais, com traficantes (Diário da Câmara dos Deputados, 2004, 13 de fevereiro, p. 5845).

Os argumentos contrários à aplicação de alternativas à prisão às condutas praticadas por usuários de drogas apoiaram-se na associação entre alternativas penais e impunidade. Punir com penas alternativas seria o mesmo que não punir, como afirmou o deputado Jefferson Campos (PMDB/SP):

A finalidade da lei é incutir temor naqueles que podem vir a ser punidos por ela. [...] O que estamos fazendo, na realidade, no meu entendimento - e não estou falando em nome do PMDB -, é a descriminalização, sim, porque haverá na cabeça daqueles que fazem uso de drogas a idéia de que não poderão ser punidos. Até as autoridades hoje incumbidas da repressão também perderão a motivação para o cumprimento do seu dever, porque saberão que não haverá pena para aquela prática (Diário da Câmara dos Deputados, 2004, 13 de fevereiro, p. 5859-5860).
Os argumentos favoráveis à aplicação das alternativas penais na Lei de Drogas não embatem essa questão, senão de forma indireta: "[...] manter na lei a pena restritiva de liberdade e a cadeia como medidas terapêuticas que podem ter algum resultado positivo nada mais é do que uma hipocrisia", como destacado pelo deputado Paulo Pimenta (Diário da Câmara dos Deputados, 2004, 12 de fevereiro, p. 5471). As alternativas penais implicariam em menor estigmatização do usuário (Diário do Senado Federal, 2006, 6 de julho, p. 22783) e estão de acordo com a ideia de reservar ao traficante as medidas severamente punitivas, possibilitando à lei "[...] tratar de forma desigual pessoas diferentes", como referido pelo deputado federal Cabo Júlio (PSC/MG) (Diário da Câmara dos Deputados, 2004, 12 de fevereiro, p. 5861). No entanto, mesmo quando se afirma que as alternativas penais aplicáveis às condutas criminalizadas relacionadas ao consumo de drogas constituiriam, de fato, penalidades, associa-se seu descumprimento ao crime de desobediência o que, então, poderia submeter o infrator a uma outra pena, essa sim, privativa de liberdade (Diário da Câmara dos Deputados, 2004, 13 de fevereiro, p. 5841).

\section{Considerações finais}

Apesar da institucionalização de alternativas às penas privativas de liberdade 
no Brasil vincular a possibilidade de utilização destas em razão de uma determinada quantidade de pena privativa de liberdade aplicada pelo juiz, é a identificação e diferenciação de sujeitos a quem devem ser destinadas diferentes respostas estatais que atravessa os discursos sobre essas práticas punitivas desde a sua emergência. A afirmação da crise do sistema prisional, o reconhecimento das precárias condições a que são submetidos aqueles condenados a penas privativas de liberdade, o entendimento de que a prisão não produz os efeitos dela esperados, não aparecem vinculadas a um discurso que coloca a necessidade de superação da centralidade do cárcere na política criminal e penitenciária, mas sim a discursos que sustentam que a prisão, em que pese não ser adequada a todo e qualquer sujeito, permanece sendo de "reconhecida necessidade" para alguns. Tendo em vista as especificidades da cultura jurídica brasileira, é preciso avaliar em que medida tais discursos, ao constituírem seus objetos desse modo, contribuem para que as penas alternativas funcionem como mais uma possibilidade de realizar essa "igualdade à brasileira", onde a diferença existente entre sujeitos é associada à desigualdade, naturalizando e justificando seu tratamento desigual em uma representação implicitamente hierárquica das relações sociais, de forma semelhante ao que ocorre, por exemplo, com a prisão especial e o foro privilegiado (KANT DE LIMA, 2008).

Quando a prisão é constituída enquanto um problema nesses termos, a questão que se coloca é identificar a quais sujeitos o cárcere não é a resposta estatal adequada quando praticam determinados crimes e diferenciá-los dos demais. Essa diferença não só está pressuposta nos discursos analisados, ao enunciarem os sujeitos que serão alvo das respostas estatais a partir da dicotomia "perigoso"//sem periculosidade", como também é pressuposta a possibilidade dessa diferenciação ser realizada, uma vez que é atribuída à autoridade judicial a necessidade de avaliação de determinados critérios relacionados ao sujeito condenado para decidir acerca da substituição ou não da pena privativa de liberdade aplicada por penas restritivas de direitos. Tais critérios encontram-se enunciados na "fórmula" materializada no art. 44 , inciso III, do Código Penal, na redação dada pela Lei 7.209/84, indicando que a substituição da pena privativa de liberdade por restritiva de direitos será possível quando: “a culpabilidade, os antecedentes, a conduta social e a personalidade do condenado, bem como os motivos e as circunstâncias indicarem que essa substituição seja suficiente" (Diário do Congresso Nacional, 1983, $1^{\circ}$ de julho, $\mathrm{p}$. 6), fórmula também utilizada como critério para avaliação da possibilidade de aplicação 
do instituto da suspensão condicional da pena.

Antes da reforma da parte geral do Código Penal, mesmo agentes considerados imputáveis, ou seja, capazes de entender o caráter criminoso do fato e de determinar-se de acordo com esse entendimento, poderiam ser considerados "perigosos" e, em razão disso, serem submetidos à pena acrescida de uma medida de segurança. A periculosidade do agente poderia ser presumida nas hipóteses definidas pela $1 \mathrm{ei}^{3}$ ou então avaliada pelo juiz na sentença ou durante a execução da pena. Nas situações em que a periculosidade não era presumida, deveria “[...] ser reconhecido perigoso o indivíduo, se a sua personalidade e antecedentes, bem como os motivos e circunstâncias do crime autorizam a suposição de que venha ou torne a delinquir" (Decreto-lei n. 2.848, 1940), conforme então determinado pelo artigo 77 do Código Penal. Comparando essa formulação para avaliação da periculosidade do sujeito com aquela posteriormente utilizada para avaliar se seria adequada a substituição da pena privativa de liberdade por uma pena restritiva de direitos, vemos uma semelhança considerável - tanto a referência quanto aos antecedentes e à personalidade do agente, quanto aos motivos e circunstâncias do crime estão presentes em ambas, sendo acrescida, no caso das alternativas penais, uma avaliação da "conduta social" do sujeito condenado.

Após a reforma, essa avaliação da periculosidade dos sujeitos imputáveis por parte do juiz foi retirada do Código Penal. No entanto, é possível que a semelhança entre essas formulações não seja casual. Se as penas diversas da prisão devem ser destinadas aos "delinquentes sem periculosidade", como distingui-los? A forma de avaliação dessa ausência ou não de periculosidade teria sido buscada na forma como os juízes já avaliavam a periculosidade dos sujeitos imputáveis antes da reforma que instituiu as penas restritivas de direitos.

A possibilidade de implementação de alternativas à pena de prisão também está relacionada ao modo como se objetiva o sujeito para o qual tais práticas serão destinadas. O modo como esses sujeitos são enunciados é utilizado estrategicamente nesses discursos, onde uma diferenciação inclusive dentre aqueles que são destinatários de alternativas penais, eventualmente até como “vítimas", pode possibilitar a implementação de práticas até então consideradas não adequadas para o campo penal. Essa centralização do modo de pensar as alternativas penais à prisão nos sujeitos a quem serão destinadas e em estratégias de diferenciação, no entanto, tende a manter sempre um espaço para aqueles sujeitos a quem as alternativas penais não são a melhor resposta 
e, portanto, afirmar a necessidade de manutenção da prisão.

Vale notar que estão presentes discursos sobre a pena como tratamento e como possibilidade de recuperação, ressocialização, reeducação. Todavia, tais discursos aparecem associados a uma diferenciação entre sujeitos que são recuperáveis, para os quais devem se destinar as novas estratégias, e sujeitos para os quais a segregação permanece sendo a resposta necessária. Considerações relativas a uma melhor administração do sistema prisional, redução da superlotação e dos custos do sistema penitenciário também se fazem presentes. As alternativas penais, desse modo, são apresentadas como uma solução mais eficiente, de menor custo, capazes de obter os resultados até então esperados da pena em termos de ressocialização, desde que orientadas para determinados sujeitos, como vemos nos discursos presentes no processo legislativo da Lei 11.343 acerca dos usuários de drogas. A prisão, por outro lado, que no momento da reforma do Código Penal em 1984, apesar de demandar aperfeiçoamento, ainda aparece como o espaço de realização do "tratamento penal", em 1996, quando da proposta de ampliação da aplicação das alternativas penais, já aparece como espaço destinado aos casos em que seja "recomendável" o isolamento social do indivíduo.
Essa multiplicidade de abordagens pode indicar que mudanças semelhantes às identificadas por Garland (2008) no campo do controle do crime dos EUA e da Grã-Bretanha a partir da década de 1970 também tenham ocorrido e estejam ocorrendo no Brasil: assim, a crise do modelo penal-previdenciário, centrado na ideia de tratamento do sujeito identificado como criminoso, não implica em um abandono das práticas e estratégias voltadas para a ressocialização, mas na sua reconfiguração a partir das perspectivas gerencialistas e atuarialistas que emergem. Assim, o ideal de ressocialização permanece como possível, mas precisa ser justificado também em termos de redução de custos e orientar-se por resultados, mensuráveis, como a redução da reincidência, considerações que terão efeitos na escolha de seu público-alvo.

Outra questão que a análise coloca em evidência é a institucionalização e a expansão das alternativas penais estar marcada por um debate acerca do quanto elas são penas realmente. Quando da discussão do projeto que resultou na Lei 9.714, o debate apresenta as alternativas à prisão como uma possibilidade de evitar a impunidade de crimes ditos "leves". Já na discussão do projeto de lei que se transformou na Lei 11.343, quando a proposta de instituir alternativas penais como sanção para as condutas relacionadas ao uso de drogas está 
sendo atacada justamente por argumentos que sustentam que isso implicaria em ausência de punição, os argumentos favoráveis a aplicação de penas diversas da prisão não afirmarão o caráter efetivamente punitivo de tais práticas estatais, mas sim as possibilidades de tratamento e reintegração social que apresentam aos sujeitos que se direcionam, compreendidos como "vítimas das drogas".

Quando tais penas ditas "alternativas" são compreendidas como não representando uma punição, elas não colocam em questão o espaço do encarceramento como pena nas práticas punitivas estatais - quando se pretende, efetivamente, punir, recorre-se à prisão. Desse modo, tais alternativas terminam afirmando a permanência daquilo a cuja crise pretendem ser uma resposta - a centralidade do cárcere. Isso não significa que a situação esteja dada e que a luta contra a prisão não possa se dar através de uma luta por alternativas à prisão. Como dito no início desse artigo, a análise dos modos como tais alternativas penais foram pensadas ao longo de sua implementação tem o potencial de colocar em evidência as racionalidades que lhes orientam. Com isso, podemos problematizar as verdades sobre o crime, sobre a punição e sobre os sujeitos criminalizados cujos efeitos de poder são uma certa confi- guração do campo penal que faz com que as “alternativas à prisão" funcionem como "alternativas além da prisão" e, assim, produzir efeitos para a sua modificação.

\section{Notas}

${ }^{1}$ Em 2008, enquanto havia 446.764 pessoas presas preventivamente ou cumprindo pena privativa de liberdade, já havia 558.830 pessoas submetidas a penas ou medidas alternativas à prisão. Disponível em: $<$ http://portal.mj.gov.br/data/Pages/MJ47E6462CITEMID38622B1FFD6142648AD402215F6598F2PTBRNN.htm>. Acesso em 31/08/2012.

${ }^{1}$ As indicações das vinculações partidárias têm caráter apenas informativo e consideram a vinculação na ocasião em que proferida a manifestação.

3 Alguns "presumidamente perigosos" previstos no Código Penal, antes da reforma de 84, no art. 70: “os condenados por crime cometido em estado de embriaguez pelo álcool ou substância de efeitos análogos, se habitual a embriaguez"; "os reincidentes em crime doloso"; "os condenados por crime que hajam cometido como filiados a associação, bando ou quadrilha de malfeitores". 


\section{Referências}

Azevedo, R. G. de. (2004). Tendências do controle penal na época contemporânea: reformas penais no Brasil e na Argentina. São Paulo em Perspectiva, 14(1), 39-48.

Barreto, F. C. O. (2010). Dez Anos da Política Nacional de Penas e Medidas Alternativas. Brasília, DF: Ministério da Justiça.

Decreto-lei n. 2.848, de 7 de dezembro de 1940. (1940, 31 de dezembro). Código Penal. Diário Oficial da União, n. 302, Seção 1, p. 2391123959. Recuperado em 19 de setembro de 2013 de http://www. planalto.gov.br/ccivil_03/decretolei/del2848.htm.

Campos, M. da S. (2010). Crime e Congresso Nacional: uma análise da política criminal aprovada de 1989 a 2006. São Paulo, SP: IBCCRIM.

Diário da Câmara dos Deputados. (1997, 20 de fevereiro), n. 20, p. 4484-4488. Diário da Câmara dos Deputados. (1997, 24 de julho), n. 25, p. 21199-21200 e 21319-21327.

Diário da Câmara dos Deputados. (2004, 12 de fevereiro), n. 19 , p. 5400-5462 e 5469-72.

Diário da Câmara dos Deputados. (2004, 13 de fevereiro), n. 20, p. 5839-5889.
Diário do Congresso Nacional. (1983, $1^{\circ}$ de julho), Seção 1, n. 80, suplemento A. Diário do Congresso Nacional. (1983, $1^{\circ}$ de dezembro), Seção 1, n. 162, p. 13654-13688.

Diário do Congresso Nacional. (1984, 16 de junho), Seção 2, n. 69, p. 2031-2032.

Diário do Congresso Nacional. (1995, 21 de janeiro), n. 15, Seção 1, p. $1157-$ 1182 .

Diário do Senado Federal. (1998, 25 de março), n. 45, p. 4934-4939.

Diário do Senado Federal. (1997, 17 de janeiro), n. 8, p. 2499-2508.

Diário do Senado Federal. (1997, 28 de janeiro), n. 15, p. 3162-3171.

Diário do Senado Federal. (1997, 15 de janeiro), n. 6, p. 2161-2217.

Diário do Senado Federal. (2006, 06 de julho), n. 112, p. 22777-22837.

Diário Oficial da União. (1998, 26 de novembro), n. 227, Seção 1, p. $37-$ 38.

Diário Oficial da União. (2006, 24 de agosto), n. 163, Seção 1, p. 6-7.

Fischer, R. M. B. (2001). Foucault e a análise de discurso em educação. Cadernos de Pesquisa, 114, 197-223.

Foucault, M. (1969/2009). A Arqueologia do Saber. 7.ed. Rio de Janeiro: Forense Universitária. 
Foucault, M. (1973/2008). A verdade $e$ as formas jurídicas. 3.ed. Rio de Janeiro, RJ: NAU.

Foucault, M. (1975/2004). Vigiar e Punir: nascimento da prisão. 29. ed. Petrópolis, RJ: Vozes.

Garland, D. (2001/2008). A Cultura do Controle: Crime e ordem social na sociedade contemporânea. Rio de Janeiro, RJ: ICC/Revan.

Instituto Latino Americano das Nações Unidas Para Prevenção do Delito E Tratamento do Delinquente Ilanud. [2006]. Levantamento Nacional sobre Execução de Penas Alternativas: relatório final de pesquisa. [S.1.]: Autor.

Kant de Lima, R. Prevenção e Responsabilidade ou Punição e Culpa? Uma discussão sobre alguns reflexos da ambiguidade de nossos modelos de controle social e produção da verdade na burocracia oficial brasileira. Em: Kant de Lima, R. Ensaios de Antropologia e de Direito. (2008). (pp. 261-289). Rio de Janeiro, RJ: Lumen Juris.

Pinto, N. M. (2006) Penas e Alternativas: um estudo sociológico dos processos de agravamento das penas e de despenalização no sistema de criminalização brasileiro (19842004). Tese de Doutorado. Curso de Pós-Graduação em Sociologia e Antropologia, Universidade Federal do Rio de Janeiro, Rio de Janeiro, RJ.

SANTOS, A. L. C. (2011). É constitucional a expansão normativa do controle social no Brasil?. Direito e Justiça: reflexões sociojurídicas, 11(16), 255-286.

Recebido em: 01/10/2013 - Aceito em: 24/01/2014 